\title{
ESTABILIZAÇÃO DO CONSUMO DE CILINDROS DE TRABALHO DO LAMINADOR DE TIRAS A FRIO DA USIMINAS*
}

\author{
Célio Souza do Rosário ${ }^{1}$ \\ Cristiano Ozores Siqueira² \\ José Dias Blanco ${ }^{3}$ \\ José Valdir Amorim Dantas ${ }^{4}$
}

\section{Resumo}

Os cilindros de laminação sempre foram ferramentas utilizadas para estudos e desenvolvimentos técnicos em laminadores, uma vez que uma instabilidade em seu consumo pode indicar alterações ou problemas no processo. Especificamente nos laminadores de tiras a frio a instabilidade representada pelo aumento no consumo dos cilindros de trabalho indica alterações no processo, na matéria-prima ou até mesmo na qualidade do próprio cilindro. Na Laminação a Frio de Cubatão já foram realizados diversos trabalhos com foco na redução de consumo de cilindros, por se tratar de um insumo de custo elevado e influência direta na qualidade do material produzido. Com o mercado consumidor de aços planos cada vez mais exigente, foi necessário desenvolver novas qualidades de aço com resistências elevadas, espessuras menores e tolerâncias dimensionais mais restritas. Para atingir este nível de exigência tornou-se necessário o investimento em equipamentos modernos, e, sobretudo, promover alterações nos processos de fabricação para a sua adequação. São estas alterações que visam atender tais exigências que podem contribuir para o aumento do consumo de cilindros. Este trabalho tem como objetivo identificar as principais causas relacionadas ao aumento do consumo dos cilindros e buscar soluções para sua estabilização.

Palavras-chave: Laminador a frio; Cilindros; Custo; Consumo.

\section{STABILIZATION OF WORK ROLLS CONSUMPTION AT USIMINAS' COLD ROLLING MILL}

\section{Abstract}

The work rolls have been always tools used for studies and technical developments in rolling mills, because instability in their consumption may indicate changes or problems at the process. Specifically in cold mills the instability represented by the increase in the consumption of work rolls indicates changes at the process, raw material or even at the quality of the roll itself. In the Cold Rolling at Cubatão's plant, several works focusing on reducing of the work roll consumption had been conducted, because it is an input of high cost and direct influence on the quality of material produced. With the increasing demand by the flat steel consumer market, it was necessary to develop new grades of steel with high resistance, smaller thicknesses and tighter dimensional tolerances. To achieve this level of demand were necessary investments in modern equipment and, above all, to promote changes in manufacturing processes for their suitability. These changes designed to meet such requirements that may contribute to the increased consumption of work rolls. This study aims to identify the main causes related to the increase of the rolls' consumption and seek for solutions for their stabilization.

Keywords: Cold rolling mill; Rolls; Cost; Consumption.

1 Engenheiro Mecânico, Gerente do Laminador de Tiras a Frio e Oficina de Cilindros da Laminação a Frio da Usiminas Cubatão, Membro da ABM, Cubatão, SP, Brasil.

2 Técnico em Mecânica, Técnico de Produção da Laminação a Frio da Usiminas Cubatão, Membro da ABM, Cubatão, SP, Brasil.

3 Técnico em Metalurgia, Assistente Técnico Industrial da Laminação a Frio da Usiminas Cubatão, Membro da ABM, Cubatão, SP, Brasil.

4 Técnico em Eletrônica, Gerente da Decapagem da Usiminas Cubatão, Membro da ABM, Cubatão, SP, Brasil.

\footnotetext{
* Contribuição técnica ao $51^{\circ}$ Seminário de Laminação - Processos e Produtos Laminados e Revestidos, 28 a 31 de outubro de 2014, Foz do Iguaçu, PR, Brasil.
} 


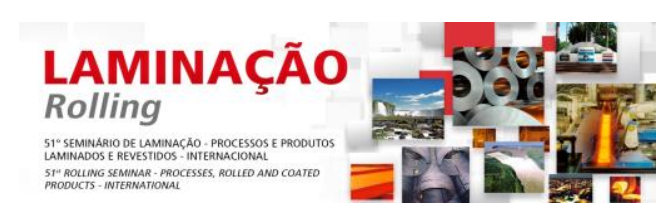

\section{INTRODUÇÃO}

O processo de laminação a frio é fundamentalmente a transformação mecânica dimensional - de tiras de aço. Essa transformação ocorre pela passagem das tiras através de cilindros (de laminação), estando elas a uma temperatura abaixo da temperatura de recristalização - quando ocorre a modificação da sua estrutura cristalina. Essencialmente o processo de laminação a frio provoca um aumento no "limite de escoamento" e na dureza do metal (Novaes, 2010).

A Figura 1 mostra o Laminador de Tiras a Frio (LTF) da Usiminas de Cubatão.

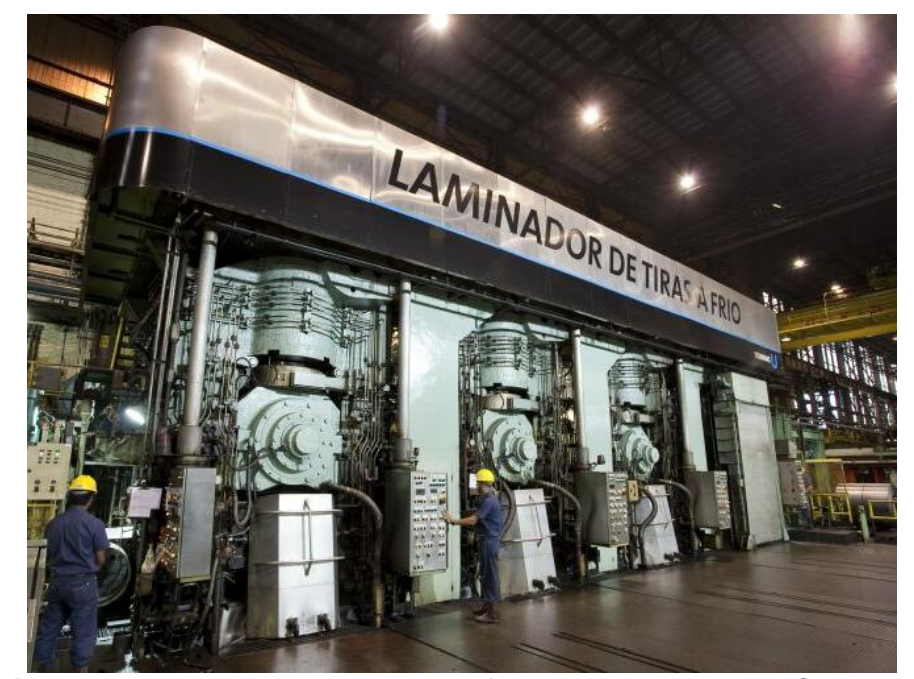

Figura 1 - Laminador de tiras a frio da Usiminas de Cubatão.

Através de uma análise da situação foi verificado que um indicador importante para ganhos de produtividade e redução de custos está ligado ao consumo de cilindros de laminação.

No processo a frio o cilindro de laminação é uma ferramenta de conformação mecânica, cujas propriedades mecânicas e metalúrgicas são ajustadas para a aplicação a que se destina (Bagger, 2011).

Os cilindros, após serem utilizados no processo, são enviados a uma oficina (de cilindros) onde são retificados para serem novamente utilizados no processo.

A quantidade de material retirado dos cilindros (pelo processo de retificação) depende dos esforços a que foram submetidos esses cilindros no laminador. Se o processo de laminação foi normal, ou seja, se os esforços foram aqueles considerados normais e, portanto, previstos, será necessário somente a remoção de uma pequena quantidade de material para eliminação da superfície endurecida (encruada), das marcas superficiais e reestabilização dos parâmetros operacionais requeridos pelo processo. Porém, quando ocorrem esforços anormais, caracterizados, normalmente, por acidentes durante a laminação, é necessário um desbaste maior para eliminação total dos defeitos consequentemente causados a fim de não comprometer o seu desempenho nas campanhas posteriores.

Sendo assim, o consumo de cilindros possui correlação direta com a estabilidade do processo de laminação a frio, porque acidentes significam instabilidade.

Quanto menor for a quantidade de material desbastado - ou retificado - dos cilindros para uma determinada produção, menor será o custo do processo de laminação de aço. 


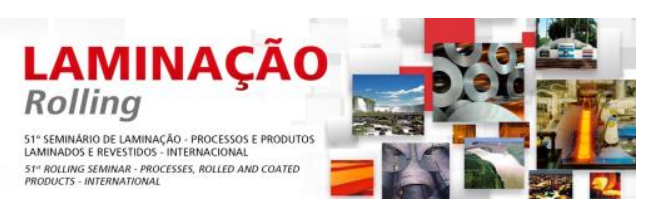

Nos últimos anos foi observada uma desestabilização no consumo de cilindros de trabalho do LTF, o que motivou a realização de diversas análises para identificação e correção dos prováveis desvios contribuintes.

\section{MATERIAL E MÉTODOS}

O primeiro passo no desenvolvimento do trabalho foi coletar os dados. Para isso foi utilizado o sistema de controle da Oficina de Cilindros - denominado $\mathrm{LOCl}$-, o qual contem todas as informações importantes relativas aos cilindros e suas campanhas no laminador, desde quando ele é novo e sem uso até o seu sucateamento, quando o cilindro atinge o fim de vida útil.

As principais informações são relativas à campanha dos cilindros no laminador e ao desbaste realizado pelas retíficas para regularização dos seus padrões de operação. Para que possamos analisar a performance dos cilindros ou a estabilidade do processo, um dos parâmetros mais importantes é o consumo específico dos cilindros de trabalho em milímetros por tonelada produzida - $\mathrm{mm} / \mathrm{t}-$, que corresponde a quantidade de material removido durante a sua retificação em função da produção realizada pelo laminador durante a campanha desse cilindro. Este valor tem que estar dentro de padrões previamente estabelecidos que consideram as trocas de cilindros por cumprimento de campanha, chamadas de "trocas previstas", e as trocas por ocorrências anormais e de naturezas diversas, as "trocas não previstas".

Em geral, os cilindros substituídos durante as trocas previstas, quando há o cumprimento da campanha por comprimento ou peso laminados, apresentam um desbaste nas retíficas inferior a $0,15 \mathrm{~mm}$ e médio de $0,11 \mathrm{~mm}$ no seu diâmetro. Já aqueles que saem durante as trocas não previstas, necessárias, por exemplo, quando há marcas causadas por irregularidades no processo, os desbastes dependem da intensidade das ocorrências e a recuperação dos cilindros é, geralmente, realizada sob o acompanhamento de um inspetor de cilindros.

O gráfico da Figura 2 apresenta os valores do consumo específico de cilindros de trabalho, obtidos ao longo dos últimos anos e meses de 2013.

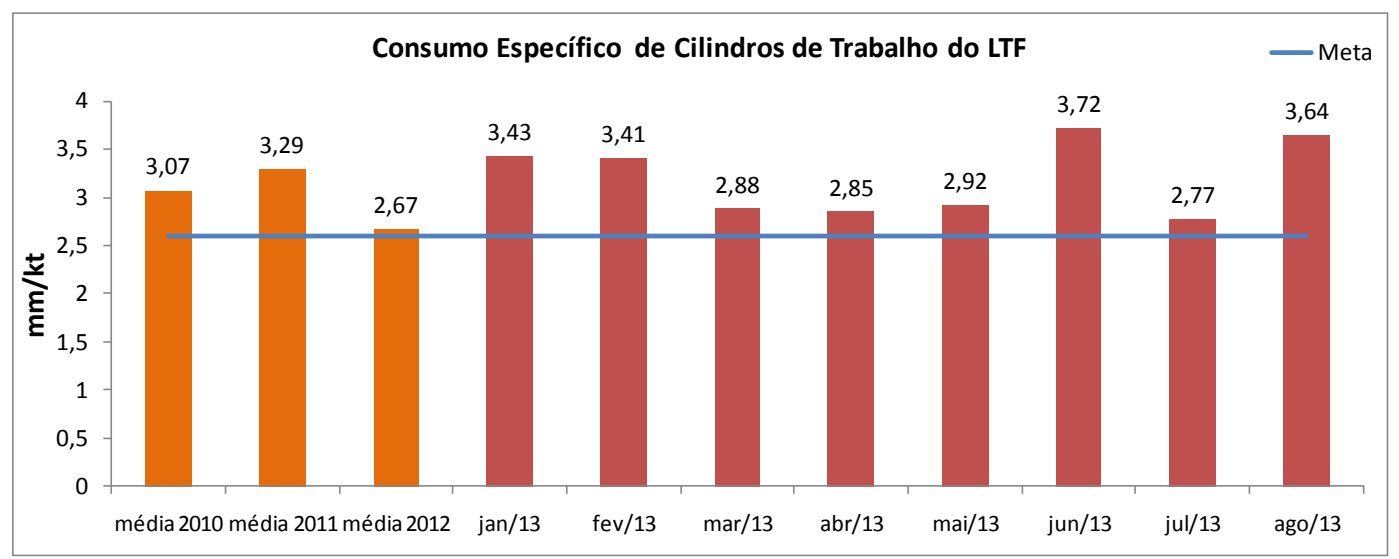

Figura 2 - Consumo específico de cilindros de trabalho do LTF.

Dentro das análises efetuadas um fato relevante que foi observado é que o desbaste médio foi de $0,20 \mathrm{~mm}$ nos cilindros que saíram em trocas previstas, ou seja, um valor acima do máximo esperado para este tipo de troca, o qual significou uma variação de cerca de $80 \%$ para mais no consumo dos cilindros. Esse aumento apontou a existência de anormalidades no processo, mesmo para cilindros trocados em razão do cumprimento de campanha.

\footnotetext{
* Contribuição técnica ao $51^{\circ}$ Seminário de Laminação - Processos e Produtos Laminados e Revestidos, 28 a 31 de outubro de 2014, Foz do Iguaçu, PR, Brasil.
} 


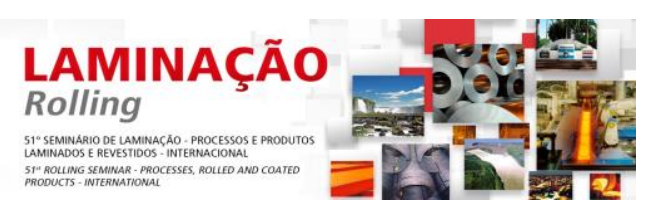

Para as trocas não previstas destacaram-se as causas principais do consumo de cilindros do LTF no período, como mostra o gráfico da Figura 3.

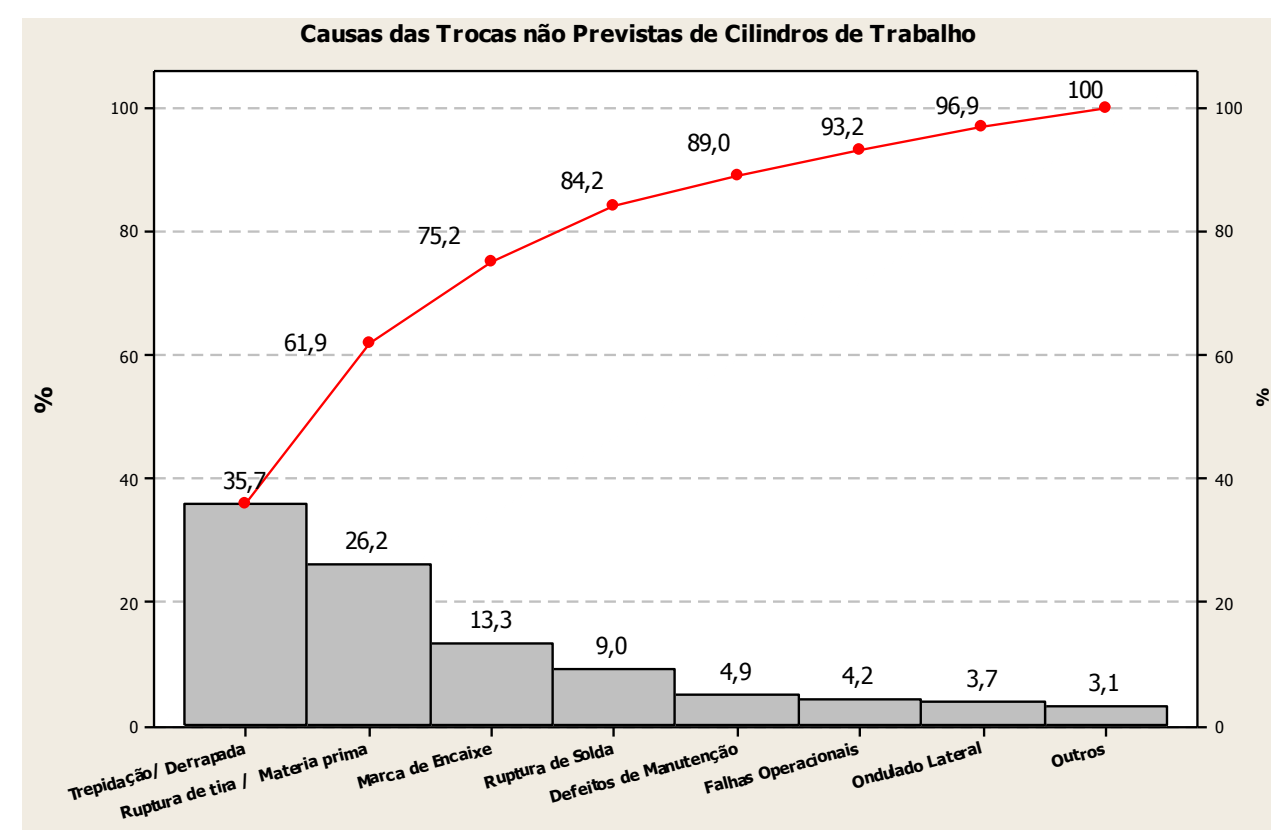

Figura 3 - Causas das trocas não previstas de cilindros de trabalho.

Uma vez estratificadas as principais causas do consumo de cilindros, foram analisados os principais fatores para a elevação do desbaste nas trocas previstas, bem como as quatro (4) principais ocorrências com maior significância para o consumo das trocas não previstas.

\subsection{Trocas Previstas}

Foi observado que cerca de $80 \%$ dos cilindros retificados, cujos desbastes foram maiores que os considerados normais, apresentaram defeitos localizados, principalmente, nas suas extremidades. Estas posições coincidiram exatamente com as larguras dos materiais laminados e assim foi possível observar marcas mais intensas do que aquelas que se tinha normalmente após o término da campanha.

Através da análise das marcas, conforme mostra a Figura 4, foi possível concluir que a origem delas estava relacionada à deficiência no aparamento das bordas do material realizado pela linha de decapagem, processo anterior ao de laminação.

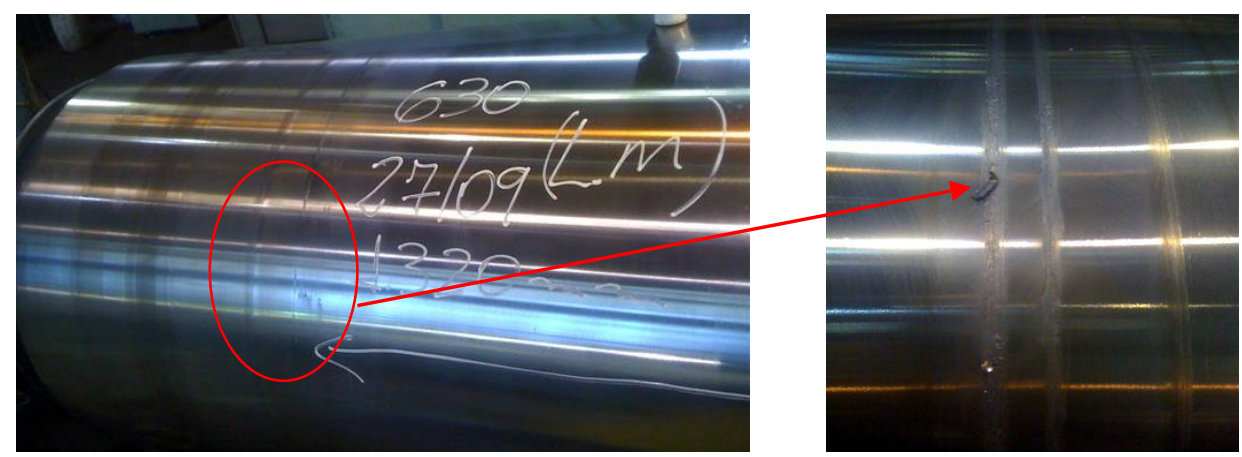

Figura 4 - Detalhe da extremidade danificada de um cilindro de trabalho.

* Contribuição técnica ao $51^{\circ}$ Seminário de Laminação - Processos e Produtos Laminados e Revestidos, 28 a 31 de outubro de 2014, Foz do Iguaçu, PR, Brasil. 


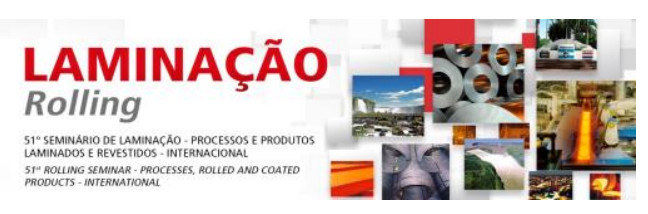

\subsection{Trocas Não Previstas}

Para as trocas não previstas serão apresentadas as principais causas, conforme ilustra o gráfico de Pareto da Figura 3.

- Trepidação/Derrapada: marcas causadas pela perda precoce da rugosidade dos cilindros, sobretudo nas cadeiras 1 e 2, em função de um aumento da produção de materiais com elevada resistência à deformação (conforme apresenta a Figura 5), aplicados para "fins elétricos", e oleamento irregular da tira durante o processo de decapagem. A perda da rugosidade é evidenciada pelo monitoramento de uma variável chamada de "escorregamento", a qual relaciona as velocidades da cadeira e da tira. Quando essa variável fica negativa, ou seja, quando a velocidade periférica dos cilindros fica maior do que a da tira na saída da cadeira, houve uma diminuição do coeficiente de atrito que está relacionado à perda da rugosidade ou ao oleamento irregular.

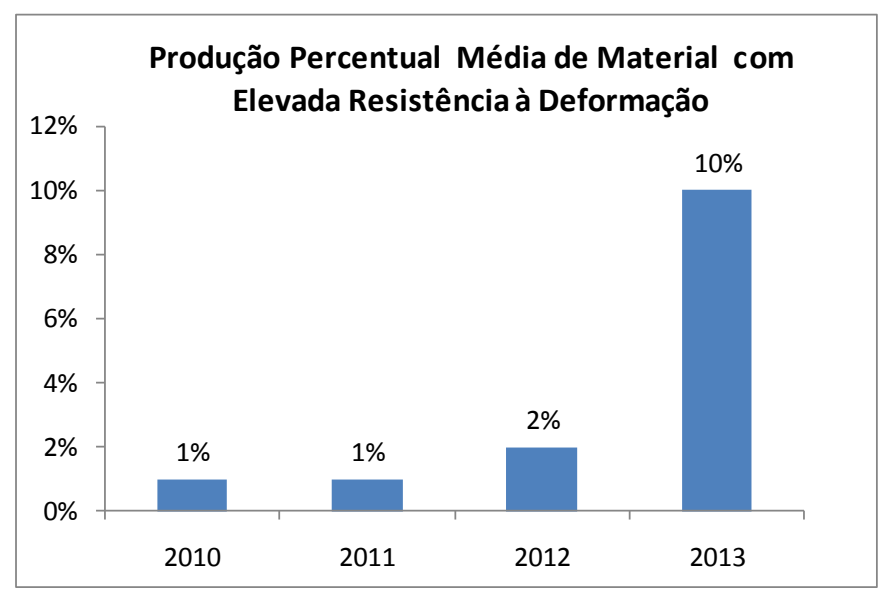

Figura 5 - Produção percentual média de material com elevada resistência à deformação em relação à produção mensal.

- Ruptura de Tira (por matéria-prima): dentre as principais causas de rupturas de tira por matéria-prima está um defeito chamado de "gota fria", o qual se apresenta como uma descontinuidade metálica na chapa sob várias formas e características a qual pode romper-se ao passar sob os cilindros de laminação, causando uma sucata do material. Normalmente a gota fria se apresenta nas duas faces (do material). A Figura 6 mostra um cilindro "acidentado" após um ruptura de tira causada pelo defeito gota fria.

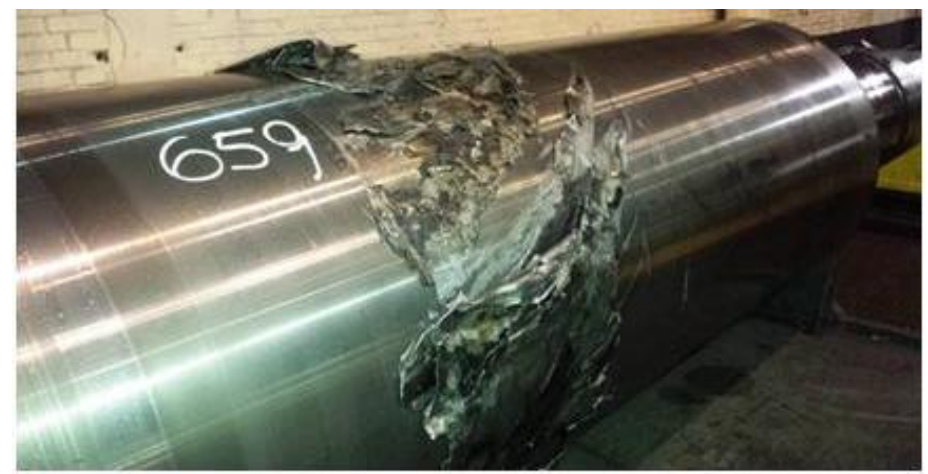

Figura 6 - Material agregado no cilindro devido a uma ruptura por "gota fria".

* Contribuição técnica ao $51^{\circ}$ Seminário de Laminação - Processos e Produtos Laminados e Revestidos, 28 a 31 de outubro de 2014, Foz do Iguaçu, PR, Brasil. 


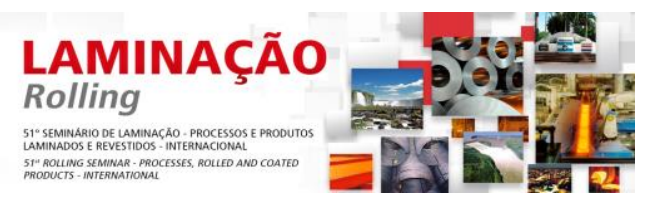

- Marca de Encaixe: marca no cilindro causada durante a fase de encaixe quando um deslizamento se torna tão intenso que propicia um arraste de material (da tira) que se adere aos cilindros de trabalho.

Esse deslizamento é causado pela falta ou diminuição significativa de atrito entre a tira laminada e os cilindros de trabalho.

- Ruptura de Solda: as rupturas estavam ligadas à quantidade de soldas efetuadas com a mesma matriz da máquina (de solda), além de estarem concentradas nos materiais com elevada resistência à deformação, aplicados, normalmente, para fins elétricos. A Figura 7 apresenta a evolução do número de rupturas de solda.

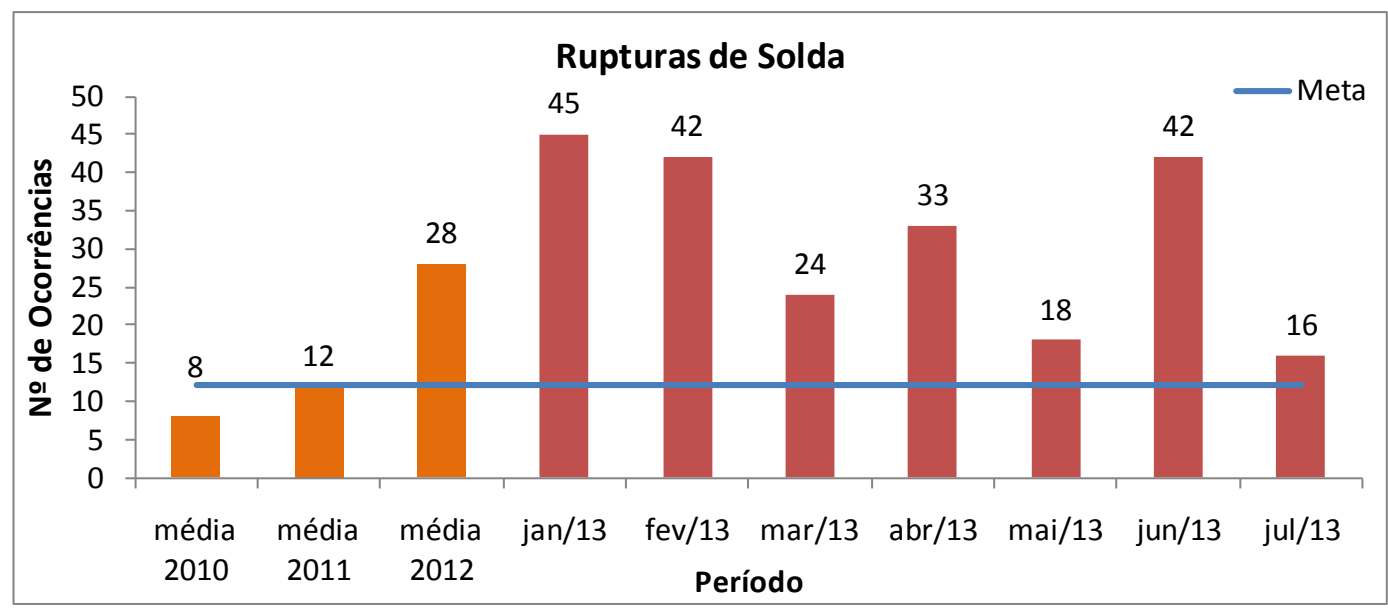

Figura 7 - Ocorrências de rupturas de solda.

\section{AÇÕES PARA REDUÇÃO DO CONSUMO DE CILINDROS DE TRABALHO}

\subsection{Normalização do aparamento na tesoura lateral da Decapagem}

A partir do problema de aparamento foram tomadas ações pela equipe de manutenção que objetivaram a correção do problema, e entre elas podem ser citadas: a revisão do plano de manutenção, o aumento da dureza das navalhas de corte, bem como a eliminação de todas as folgas (acima os valores permitidos) que por ventura existiam no equipamento.

\subsection{Normalização do oleamento da tira a partir da oleadeira eletrostática da nova Decapagem 3}

Um dos principais motivos de desbaste de cilindros, conforme ilustra o gráfico da Figura 3 acima, era o oleamento irregular da tira. Esse oleamento irregular propicia o aumento do atrito na cadeira (entre a tira e o cilindro) que causa um desgaste anormal do cilindro e gera um defeito chamado de "marca de atrito" no material, principalmente, nas cadeiras 1 e 2 .

A Figura 8 mostra marcas de atrito na "mesa" de um cilindro de trabalho.

\footnotetext{
* Contribuição técnica ao 51Seminário de Laminação - Processos e Produtos Laminados e Revestidos, 28 a 31 de outubro de 2014, Foz do Iguaçu, PR, Brasil.
} 


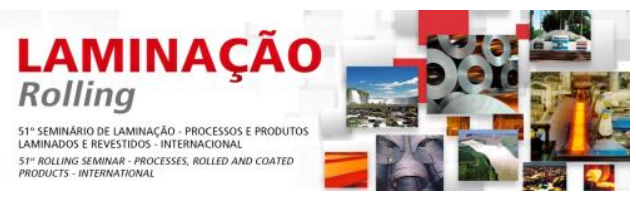

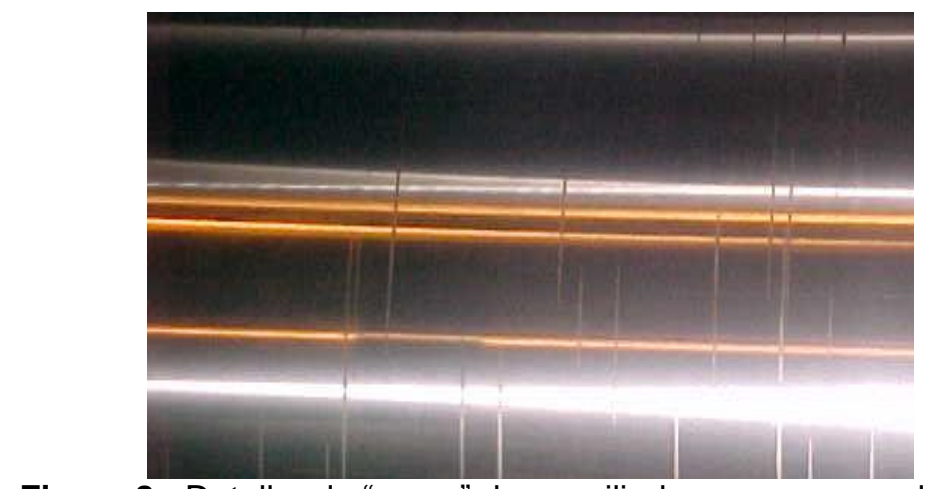

Figura 8 - Detalhe da "mesa" de um cilindro com marcas de atrito.

Com a entrada em operação da nova linha de decapagem o oleamento passou a ser feito por uma oleadeira eletrostática (Figura 9), a qual garante a uniformidade da camada de óleo aplicada sobre a tira. Dessa forma, os problemas de atrito/derrapada diminuíram consideravelmente.

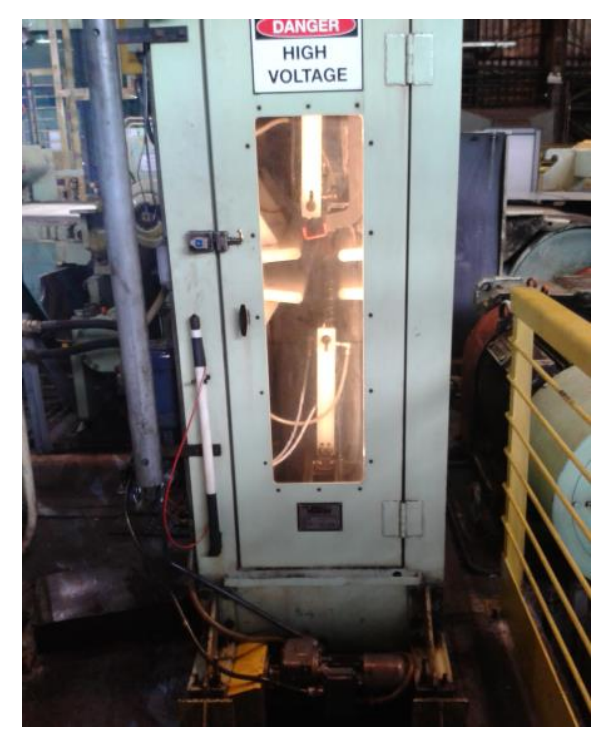

Figura 9 - Oleadeira eletrostática da linha de decapagem.

\subsection{Plano de ação para eliminação do problema de "gota fria" na Aciaria}

A partir do problema de "gota fria" e das suas consequências no LTF foi discutido um plano de ação cujas ações foram efetivas na redução do problema. Entre essas ações podem ser citadas:

- Alteração nos procedimentos de manutenção para garantir o alinhamento e o espaçamento correto entre os rolos da máquina de lingotamento contínuo.

- Alteração no padrão de liberação de placas no setor de Escarfagem para materiais destinados à Laminação a Frio.

\subsection{Modificação do momento de retirada do "over gap" durante o encaixe da tira nos cilindros}

O encaixe da tira na cadeira depende do coeficiente de atrito, e, consequentemente, da rugosidade do cilindro. À medida que há a perda dessa rugosidade o encaixe fica prejudicado. Com a retirada automática do "over gap" - sobre gap de espera - após o encaixe da tira na cadeira, associada à falta de atrito, ocorria uma trepidação dos

\footnotetext{
* Contribuição técnica ao $51^{\circ}$ Seminário de Laminação - Processos e Produtos Laminados e Revestidos, 28 a 31 de outubro de 2014, Foz do Iguaçu, PR, Brasil.
} 


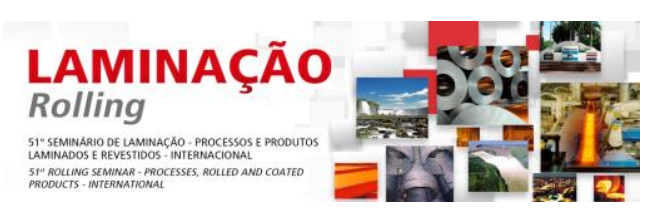

cilindros sobre a tira, os quais não conseguiam tracioná-la, gerando marcas nos próprios cilindros. Dessa forma foi alterada a lógica para que, somente após a tira encaixar na cadeira 2, o over gap da cadeira 1 seja retirado, fazendo com que a cadeira 2 ajude a "tracionar" o material, evitando-se assim trepidações e marcas nos cilindros quando o atrito já está menor pela perda da rugosidade.

\subsection{Redução do coroamento mecânico dos cilindros}

Após a entrada do novo laminador a quente houve uma mudança das características dos materiais (a quente) produzidos, sobretudo da coroa e da cunha, cujos valores passaram a ter uma menor dispersão e ser mais adequados à forma do material para o processamento a frio.

A partir daí foi necessário corrigir o coroamento mecânico dos cilindros de trabalho a afim de que eles se adequassem à forma dos materiais agora fornecidos, com os objetivos de se garantir a planicidade e mitigar a ocorrência de defeitos de forma, tais como ondulações laterais ou centrais.

\subsection{Adequação do nivelamento e dos compensadores de coroa}

O modelo matemático e a prática operacional até então utilizada estavam adequados aos materiais produzidos apenas pelo antigo laminador a quente. Durante uma fase de transição, com materiais oriundos de dois "fornecedores" diferentes, houve a necessidade de atuações para que o processo e a forma do material (processado) atendessem as especificações.

Assim, houve a necessidade de uma adequação operacional no modo de se atuar no nivelamento das cadeiras e nos compensadores de coroa, padronizando-se os procedimentos de encaixe e desencaixe do material.

Para efetivação da ação, foram realizados treinamentos operacionais com o objetivo de disseminar as melhores práticas adquiridas durante o acompanhamento do suporte técnico.

\subsection{Soldagem do material na Decapagem}

Um levantamento realizado mostrou que a média de rupturas de tira estava alta, o que impactava significativamente no consumo de cilindros.

Um estudo mostrou que a ocorrência de rupturas estava ligada à quantidade de soldas efetuadas com a mesma matriz da máquina (de solda). Foi, então, implantado um controle da quantidade de soldas efetuadas de forma a se estabelecer um limite máximo até que seja necessária a substituição da matriz.

Como a maioria das rupturas de solda estava concentrada em materiais para fins elétricos e com foi evidenciado um aumento significativo da quantidade desse material, também foi necessário alterar o padrão de regulagem da máquina de solda, além de treinar a equipe de operação nesse novo padrão.

\section{RESULTADOS OBTIDOS}

Após a implementação das ações houve uma diminuição significativa na quantidade de rupturas, o que contribuiu para a diminuição das marcas nos cilindros. O gráfico da Figura 10 apresenta a evolução da redução das rupturas de solda.

\footnotetext{
* Contribuição técnica ao $51^{\circ}$ Seminário de Laminação - Processos e Produtos Laminados e Revestidos, 28 a 31 de outubro de 2014, Foz do Iguaçu, PR, Brasil.
} 


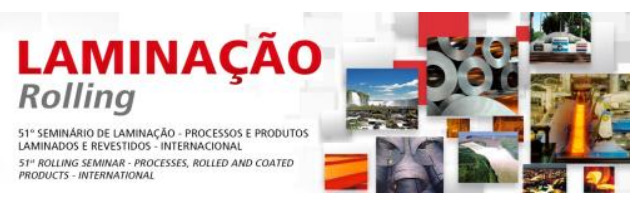

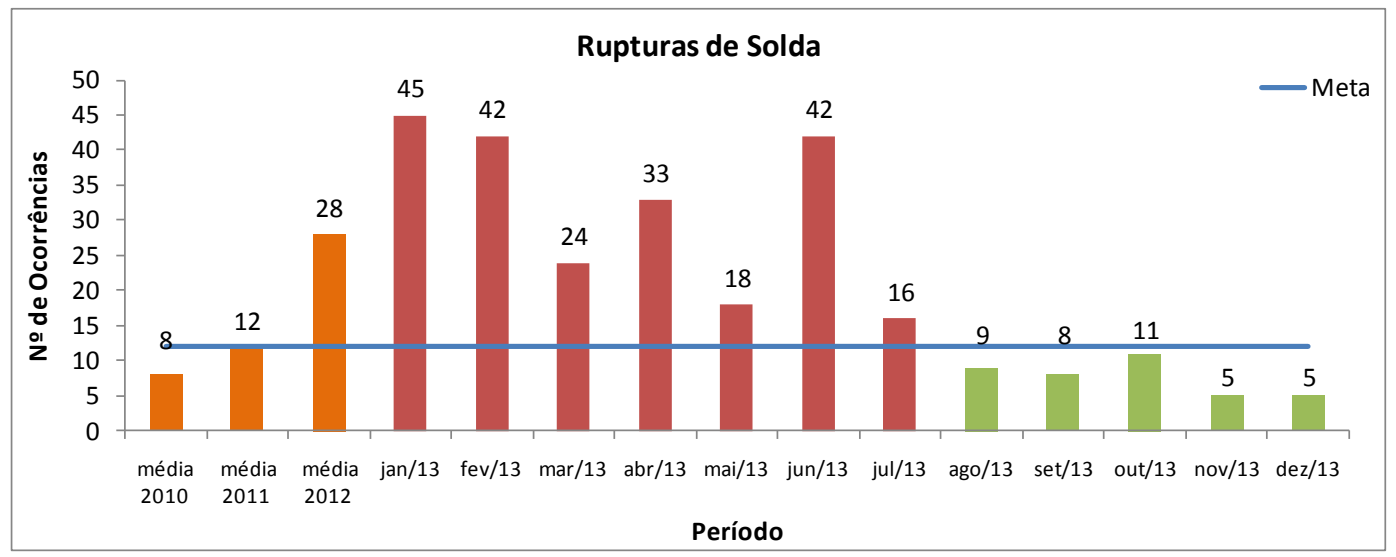

Figura 10 - Rupturas de solda no LTF após a implementação das ações.

Após as ações descritas acima houve uma diminuição significativa no consumo de cilindros, conforme é apresentado pelo gráfico da Figura 11.

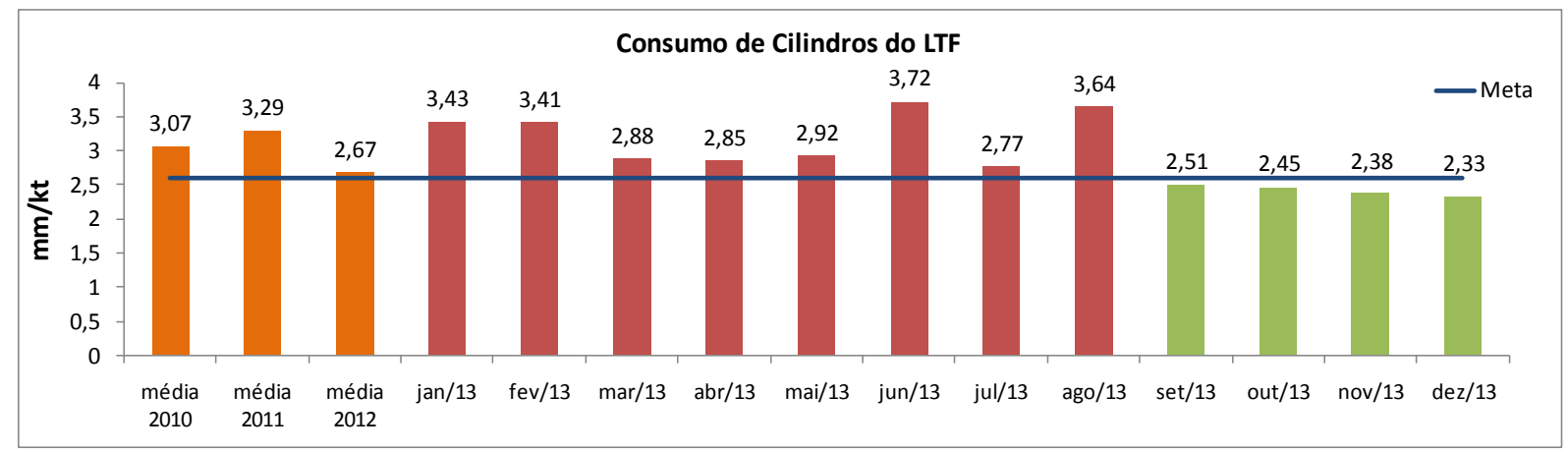

Figura 11 - Consumo de cilindros de trabalho no LTF após as ações.

\section{CONSIDERAÇÕES FINAIS}

Após os estudos realizados a respeito do aumento do consumo de cilindros foi possível identificar suas principais causas e atuar de forma preventiva e corretiva em variáveis do processo para que uma diminuição desse consumo fosse obtida.

A instalação de novas linhas de processo contribuiu diretamente para a qualidade do material e indiretamente para a diminuição do consumo de cilindros.

O trabalho objetivou uma diminuição com estabilização dos resultados, porém foi observado que há a possibilidade de se atuar em outras variáveis para que novos resultados positivos em relação à diminuição possam ser alcançados.

Uma análise posterior em relação à aplicação de uma camada de cromo nos cilindros de trabalho, avaliando-se os ganhos para o consumo e aumento da campanha, deve ser realizada, visto que testes preliminares já demonstraram resultados positivos.

* Contribuição técnica ao $51^{\circ}$ Seminário de Laminação - Processos e Produtos Laminados e Revestidos, 28 a 31 de outubro de 2014, Foz do Iguaçu, PR, Brasil. 